\section{Otoritas Atasan, Retaliasi dan Locus of Control sebagai Faktor-Faktor yang Memengaruhi Perilaku Manipulasi Laporan Realisasi Anggaran}

\author{
Hafiez Sofyani \\ Fakultas syariah dan Ekonomi Islam IAIN Antasari Banjarmasin \\ Email: hafiezgambut@gmail.com \\ Yulinda Devi Pramita \\ Fakultas Ekonomi Universitas Muhammadiyah Magelang
}

\begin{abstract}
The purpose of this study was to examine the influence of situational factors such as the authority that deligated from superior and retaliation; and individual factors such as locus of control toward individual's ethical behavioral in budget realization reporting. This study used experiment design with $2 \times 2$ factorial. The results of this study indicate that the condition there were authority that deligated from superior to commit fraud and retaliation from superior if orders do not to be implemented, tend to influence individual to act unethically, namely makes the budget realization reports that was not fit. In addition, individu with an external locus of control while against conditions got the authority to made fraudulent statements and got retaliation if did not carry out the order, will tend to be more unethical than individu with an internal locus of control. However, the hypothesis that states if there is no authority that deligated from superior, no retaliation and individual has internal locus of control would be the most ethical act among other situations, in this study was not supported.
\end{abstract}

Key words: The authority of superiors, Retaliation, Locus of control, Fraudulent statements

\section{PENDAHULUAN}

Maraknya isu perilaku tidak etis dikalangan akuntan, baik akuntan di sektor bisnis maupun sektor pemerintahan, menjadi topik hangat dewasa ini. Menurut Cohen dkk. (1993), masalah perilaku etis akuntan dalam beberapa dekade ini telah banyak menjadi sumber perhatian dan kepentingan penelitian. Perilaku etis akuntan yang paling sering ditemui adalah pada saat pelaporan keuangan. Di lembaga sektor publik, khususnya pemerintahan, kecurangan pelaporan yang paling sering terjadi diduga terjadi pada saat pelaporan keuangan yang terkait pengadaan dan renovasi aset pemerintah, seperti rumah dinas, kendaraan, dan sarana-prasarana.

Di sektor privat, kecurangan pelaporan keuangan dapat secara langsung merugikan pemegang saham dan kreditur dari perusahaan penerbit laporan keuangan selama kecurangan yang dilakukan dapat merugikan seluruh investasi perusahaan, seperti mengakibatkan kebangkrutan atau kegagalan perusahaan (Raab, 1987). Perilaku kecurangan pelaporan dalam jumlah yang kecil maupun besar yang dilakukan perusahaan dapat memberikan dampak ketidakpercayaan investor dan kreditor terhadap laporan keuangan perusahaan (Raab, 1987).

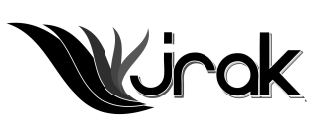

Jurnal Reviu Akuntansi dan Keuangan ISSN: 2088-0685 Vol.3 No. 2, Oktober 2013 Pp 427-436 
The Evidence of Goodwill...

Kecurangan pelaporan yang kerap dilakukan akuntan bisa dipengaruhi oleh faktor internal, seperti; tingkat penalaran moral, locus of control, empati, self interest, responsibilitas; dan faktor eksternal (situasi) seperti; otoritas dari atasan untuk melakukan kecurangan, ada tidaknya kewajiban penyampaian laporan ke publik, ancaman retaliasi (pembalasan dendam), kesempatan, dan tekanan dari orang lain (Trevino, 1986; Tsui \& Ferdinand, 1996; Rotter, 1996; Ponemon, 1992; Rutledge dkk, 1999; Liyanarachchi dan Chris Newdick, 2009; Mayhew dan Murphy, 2008, 2012).

Faktor eksternal khususnya situasional menarik untuk dibahas karena banyak pendidik setuju bahwa para siswa melakukan kecurangan didalam kelas disebabkan oleh faktor situasional yang lebih atraktif untuk melakukan kecurangan (Day, Hudson, Roffol, \& Robert, 2011). Salah satu penelitian yang menguji pengaruh faktor situasional yaitu otoritas untuk melakukan kecurangan terhadap perilaku kecurangan pelaporan dilakukan oleh Murphy \& Mayhew (2012) yang menemukan bahwa otoritas atasan untuk melaporkan lebih dari seharusnya memengaruhi individu untuk berperilaku tidak etis dengan mengalihkan atau menggeser tanggungjawab atas perilaku kecurangan tersebut kepada pemberi otoritas.

Namun, penelitian Murphy \& Mayhew (2012) hanya menguji faktor situasional sebagai faktor yang memengaruhi perilaku pengambilan keputusan etis individu dan tidak memasukkan faktor individual. Faktor individual menjadi penting untuk dipertimbangkan karena proses pengambilan keputusan seseorang tidak dapat dilihat secara parsial hanya dari faktor situasional saja, melainkan juga harus mempertimbangkan faktor yang melekat pada individu yang dapat memengaruhi keputusan yang diambil.

Beberapa penelitian yang menguji pengaruh faktor individual seperti penalaran moral dan locus of control terhadap perilaku etis seseorang dilakukan oleh Trevino (1986), Tsui \& Ferdinand (1996), dan Rotter (1996). Beberapa penelitian tersebut menyimpulkan bahwa penalaran moral dan locus of control dari seseorang akan memengaruhi mereka dalam berperilaku etis.

Selain faktor situasional (otoritas atasan) dan faktor individual (locus of control), penelitian ini juga memasukkan faktor pembalasan (retaliasi) sebagai faktor situasional tambahan. Faktor retaliasi ini menarik dimasukkan karena faktor otoritas atasan untuk membuat laporan yang tidak sesuai sebagaimana mestinya berkemungkinan akan mendapat penolakan dari individu yang memiliki internal locus of control ketimbang mereka yang memiliki external locus of control. Ketika perintah atasan tidak dipatuhi oleh bawahannya, maka atasan akan berkemungkinan melakukan retaliasi dengan beberapa alternatif cara, seperti; memindah tugaskan, mengurangi insentif, atau bahkan memecat akuntannya (Liyanarachchi \& Newdick, 2009; Tsui \& Ferdinand 1996). Dalam posisi terdapat retaliasi, "apakah akuntan yang memiliki internal locus of control akan tetap berlaku etis dengan cara menolak perintah atasannya atau luluh dan mau menerima perintah atasannya untuk berlaku tidak etis?", secara empiris belum ada penelitian yang mengujinya.

Di samping itu, penelitian terdahulu yang dilakukan beberapa peneliti (Murphy \& Mayhew, 2012; Liyanarachchi \& Newdick, 2009; Tsui \& Ferdinand 1996) dalam menguji pengaruh faktor situasional dan faktor individual terhadap perilaku etis akuntan dilakukan secara terpisah. Padahal, pertimbangan etis seseorang ketika menghadapi dilema etika adalah proses yang komprehensif dan rumit. Sehingga, penghadiran dilema etika, yakni faktor situasional dan individual secara bersamaan pada satu situasi yang dihadapi individu akan memberikan gambaran sesungguhnya dari perilaku etis individu tersebut.

Sehingga, Eksperimen dalam penelitian ini menguji bagaimana pengaruh faktor situasional dan faktor individual terhadap perilaku kecurangan pelaporan. Perilaku pelaporan pada eksperimen ini merupakan pengganti perilaku pelaporan keuangan lingkungan kerja nyata. Persepsi perilaku individu dikelas dapat dipertimbangkan sebagai penyulih persepsi perilaku masa depan individu pada dunia bisnis (Allmon, Page, \& Roberts, 2000) atau sektor publik untuk konteks penelitian ini. 


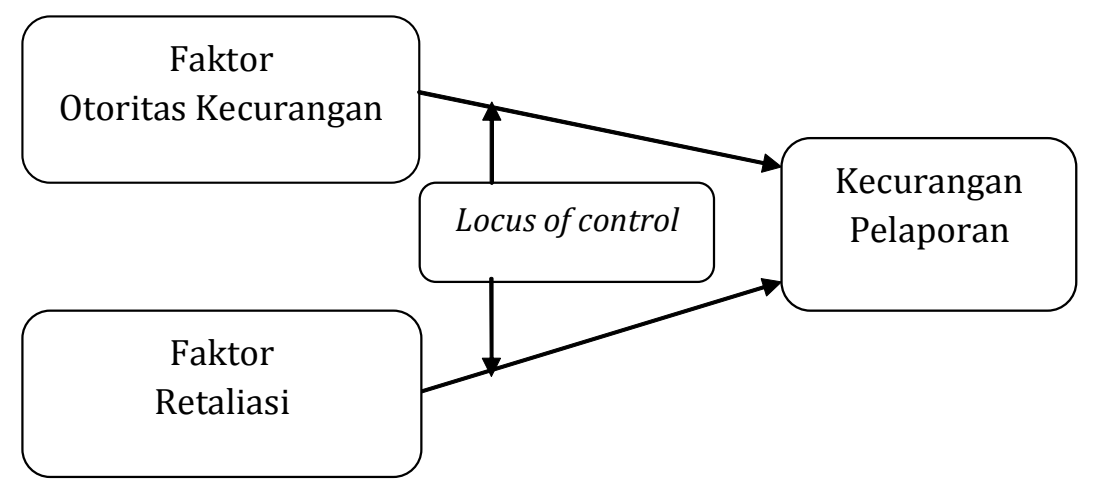

\section{Kerangka Teoritis dan Pengembangan Hipotesis}

\section{Kecurangan Pelaporan Keuangan (Fraudulent Financial Statement)}

Kecurangan pelaporan merupakan salah satu jenis kecurangan manajemen (management fraud) (Singleton \& Singleton, 2010). Kecurangan manajemen adalah niatan melakukan kecurangan pelaporan keuangan perusahaan untuk meningkatkan kinerja manajemen dengan harapan mendapatkan keuntungan, seperti promosi jabatan, bonus dan insentif ekonomi lainnya (Singleton \& Singleton, 2010). Skema kecurangan pelaporan keuangan dapat dikategorikan menjadi kecurangan finansial dan non-finansial.

Kecurangan yang dilakukan oleh individu merupakan suatu perilaku yang didasari oleh faktor eksternal dan internal individu itu sendiri (Murphy \& Mayhew (2012). Hal tersebut juga mengindikasikan perihal sama terkait tindakan etis seseorang (Liyanarachchi \& Newdick, 2009; Tsui \& Ferdinand 1996).

\section{Faktor Situasional}

\section{Otoritas Atasan dan Ancaman Pembalasan (Retaliasi)}

Murphy \& Mayhew (2012) menemukan otoritas atasan untuk melaporkan lebih dari seharusnya memengaruhi individu untuk berperilaku taketis dengan mengalihkanatau menggeser tanggungjawab atas perilaku kecurangan tersebut kepada pemberi otoritas. Individu yang diperintahkan melakukan tindakan tidak etis oleh atasannya akan mematuhi perintah tersebutkarena dia melihat dirinya sebagai alat untuk melakukan tindakan taketis oleh atasannya, sehingga dirinya merasa tidak perlu bertanggung jawab atas tindakan tersebut (Milgram, 1974).

Kebanyakan dari studi akuntansi keperilakuan yang memasukkan variabel retaliasi selalu berkaitan dengan aksi melaporkan pelanggaran (witsleblowing). Padahal retaliasi sesungguhnya tidak hanya terjadi pada kasus witsleblowing saja, tetapi juga peristiwa lain seperti pembangkangan bawahan kepada atasan atas dasar self interst, iri karena jabatan diambil alih orang lain, dan tuntutan yang tidak dipenuhi. Bok pada tahun 1980 sudah menyebutkan ada banyak bentuk retaliasi, yaitu; penurunan level jabatan, pemberian kerja tanpa tanggung jawab, pemberian kerja lebih banyak dengan upah tetap, dan pemberian pekerjaan dengan membutuhkan kemampuan atau kualifikasi baru sebagai bentuk-bentuk retaliasi terhadap pelaku witslebloeing (Liyanarachchi \& Newdick, 2009).

Kedua faktor situasional (otoritas dan retaliasi) yang berinteraksi dapat memberikan kombinasi yang kuat untuk melakukan kecurangan pelaporan atau dapat menjadi kombinasi yang dapat memperlemah perilaku kecurangan pelaporan. Kombinasi situasi keduanya menjadi hal yang lebih mendekati kondisi sesungguhnya pada sebuah organisasi. Dua penelitian sebelumnya yang menguji faktor situasional secara terpisah membuat gap eksperimen tersebut dari kondisi sesungguhnya. 
The Evidence of Goodwill...
Interaksi faktor situasional tersebut diharapkan dapat lebih menjelaskan bagaimana otoritas dan kondisi sosial memengaruhi perilaku kecurangan pelaporan dibandingkan keduanya dipisahkan. Hal tersebut dapat mengurangi gap eksperimen sebelumnya dengan kondisi senyatanya karena proses individu mengambil keputusan merupakan fenomena rumit yang tidak dapat dilihat secara parsial. Berdasarkan argumen tersebut maka dibangung hipotesis sebagai berikut:

H1a: Diduga kecurangan pelaporan ditemukan paling tinggi pada kondisi terdapat otoritas kecurangan dan pembalasan (retaliasi) dibandingkan kondisi lainnya.

H1b: Diduga kecurangan pelaporan ditemukan paling rendah pada kondisi tidak terdapat otoritas kecurangan dan tidak ada pembalasan (retaliasi) dibandingkan kondisi lainnya.

\section{Faktor Individual \\ Locus of Control}

Rotter (1990) mengemukakan locus of control merupakan pengendalian internal dan eksternal yang mengarah kepada tingkat ekspektasi seseorang bahwa perilaku reinforcement atau outome sebagai kontinjensi perilaku dalam mendapatkan sesuatu atau karakteristik personal dibandingkan dengan tingkat ekspektasi seseorang bahwa reinforcement atau outome berupa perubahan fungsi, keuntungan, nasib dibawah pengendalian yang kuat atau tidak bisa diprediksi.

Penelitian Tsui \& Ferdinand (1996) menemukan bahwa faktor individual, yaitu locus of control, mampu memengaruhi seseorang dalam bertindak etis. Dalam penelitian Tsui \& Ferdinand (1996) tersebut, seseorang dengan internal locus of control akan berani bertindak etis pada saat menghadapi konflik audit dengan tetap melaporkan temuannya yang tidak wajar dibanding individu yang memiliki external locus of control. Oleh karenya, dalam kasus pembuatan pelaporan, seseorang dengan internal locus of control diprediksi akan tetap bertindak sesuai kesadaran analitikalnya, dan bukan berdasarkan otoritas atasan yang menyuruh kepada tindakan tidak etis. Inilah landasan bahwa faktor individual juga mampu memengaruhi perilaku kecurangan seseorang.

Otoritas atasan yang menyarankan kepada penyusun laporan untuk melaporkan hal yang lebih menguntungkan dapat membuat penyusun laporan melimpahkan tanggung jawab (responsibility shifting) laporan tersebut kepada atasannya. Dalam kondisi penyusun laporan tidak diberikan otoritas dari atasan untuk melaporkan hal yang lebih menguntungkan, maka individu akan lebih berhati-hati untuk melakukan kecurangan pelaporan karena tanggungjawab perilaku kecurangan sepenuhnya ditanggung oleh penyusun laporan tersebut (Murphy \& Mayhew (2012). Situasi tersebut diperparah jika ditambah adanya ancaman pembalasan dendam dari atasan jika perintahnya tidak dituruti. Individu yang tadinya berusaha untuk tetap berperilaku etis bisa jadi terpengaruhi dan terpaksa bertindak tidak etis karena memperoleh ancaman pembalasan dendam dari pihak yang lebih tinggi kedudukannya (Liyanarachchi \& Newdick, 2009).

Dalam kondisi mendapat otoritas melakukan kecurangan pelaporan dan ancaman pembalasan (retaliasi) jika perintah tidak dilaksanakan, individu yang memiliki external locus of control cenderung untuk melakukan kecurangan pelaporan karena orang yang memiliki external locus of control akan bergantung pada nasib dari sikap atasannya, sehingga mereka akan lebih cenderung untuk berperilaku tidak etis daripada orang dengan internal locus of control yang mampu merasionalisasi dan mengendalikan perilaku mereka (Liyanarachchi \& Newdick, 2009; Murphy \& Mayhew, 2012; Tsui \& Ferdinand, 1996). Demikian pula internal yang percaya bahwa peristiwa berada di bawah kendali mereka akan bertanggungjawab dalam penentuan perilaku benar dan salah mereka, sehingga mereka akan berperilaku lebih etis daripada orang dengan external locus of control (Trevino, 1986). Berdasarkan argumen tersebut maka penulis mengajukan hipotesis sebagai berikut: 
$\mathrm{H} 2 \mathrm{a}$ : Diduga perilaku kecurangan pelaporan ditemukan paling tinggi pada situasi terdapat otoritas atasan dan ada ancaman pembalasan (retaliasi) serta individu memiliki external locus of control dibandingkan situasi lainnya.

H2b: Diduga perilaku kecurangan pelaporan ditemukan paling rendah pada situasi tidak ada otoritas atasan dan tidak ada ancaman pembalasan (retaliasi) serta individu memiliki internal locus of control dibandingkan situasi lainnya.

\section{METODE}

Penelitian ini menggunakan pendekatan eksperimen dengan desain 2 x 2 faktorial between subject, yaitu desain eksperimen yang secara simultan mengakomodasi penelitian atas pengaruh dua atau lebih variabel independen, baik pengaruh utama maupun pengaruh interaksi terhadap variabel dependen. Desain ini bermanfaat untuk pelaksanaan eksperimen yang mempunyai dua atau lebih variabel independen (disebut faktor) dengan masing-masing faktor memiliki paling sedikit dua level (Nahartyo, 2012).

Partisipan (subjek eksperimen) penelitian ini adalah mahasiswa jurusan Akuntansi Universitas Muhammadiyah Magelang dengan kriteria sudah menempuh matakuliah Akuntansi Manajerial dan Akuntansi Sektor Publik. Pemilihan partisipan dengan kriteria di atas dimaksudkan agar sampel sudah memiliki pemahaman yang baik terkait masalah penyusunan laporan realisasi anggaran di lembaga pemerintahan. Meskipun partisipan adalah mahasiswa yang belum bekerja dan belum memiliki atasan, untuk menciptakan kondisi yang sama dengan yang terjadi di kontek dunia kerja, peneliti membuat manipulasi yang diberikan melalui studi kasus yang menjelaskan posisi partisipan dalam kasus tersebut. Manipulasi akan di cek keberhasilannya sebelum partisipan mengerjakan kasus eksperimen.

\begin{tabular}{lcc}
\hline \multirow{2}{*}{ Faktor otoritas } & \multicolumn{2}{c}{ Faktor retaliasi } \\
\cline { 2 - 3 } \multicolumn{1}{c}{ Ada retaliasi } & Tidak ada retaliasi \\
\hline Dengan otoritas pelaporan & Sel 1 & Sel 2 \\
Tanpa otoritas pelaporan & Sel 3 & Sel 4 \\
\hline
\end{tabular}

Tabel 1. Desain Eksperimen dan Pengujian H1a, H1b

Partisipan dibagi ke dalam empat sel yang berbeda dengan perlakuan seperti yang digambarkan pada desain eksperimen di bawah ini;

Sebelum penelitian eksperimen dilakukan, peneliti melakukan cek manipulasi untuk menentukan apakah partisipan siap untuk mengikuti eksperimen atau tidak. Selanjutnya, penelitian dilakukan dengan dua sesi, pertama; partisipan diminta mengisi kuesioner yang digunakan untuk menentukan posisi locus of control para partisipan. Pada sesi kedua; partisipan diminta untuk menjawab carita kasus yang diajukan oleh peneliti.

Hipotesis penelitian diuji dengan uji contrast pada analysis of variance (ANOVA). Uji contrast dilakukan untuk membanding-kan antara satu sel dengan sel lainnya (Kerlinger \& Lee, 2000). H1a dijawab dengan membanding-kan Jumlah Kecurangan Pelaporan (JKP) antara sel 2 dengan sel 1, 3 dan 4 pada table 1. Hipotesis akan terdukung apabila JKP sel 1 memiliki nilai paling tinggi dibandingkan sel 2, 3 dan 4. H1b dijawab dengan membandingkan JKP antara sel 4 dengan sel 1, 2 dan 3 pada table 1. Hipotesis akan terdukung apabila JKP sel 4 memiliki nilai paling rendah dibandingkan sel 1, 2 dan 3 secara jumlah matematika dan secara uji statistik.

H2a diuji dengan membandingkan data JKP partisipan sel 1 dengan sel 2, 3, 4, 5, 6, 7 dan 8 pada tabel 2. Sedangkan H2b diuji dengan membanding-kan data JKP partisipan sel 7 dengan sel 1, 2, 3, 4, 5, 6, dan 8 pada tabel 2 . H2a dan 
The Evidence of Goodwill...
Tabel 2. Desain Eksperimen dan Pengujian H2a dan $\mathrm{H} 2 \mathrm{~b}$

Tabel 3.

Data Demografi

Tabel 4. Statistik Deskriptif Desain Eksperimen H1
H2b akan terdukung ketika ditemukan JKP pada sel 1 paling tinggi dan sel 7 paling rendah dibandingkan sel lainnya secara jumlah matematika dan secara uji statistik dengan menggunakan uji contrast pada ANOVA.

\begin{tabular}{|c|c|c|c|c|}
\hline \multirow{3}{*}{$\begin{array}{l}\text { Faktor } \\
\text { otoritas }\end{array}$} & \multicolumn{4}{|c|}{ Faktor retaliasi } \\
\hline & \multicolumn{2}{|c|}{ Ada retaliasi } & \multicolumn{2}{|c|}{ Tidak ada retaliasi } \\
\hline & ILC & ELC & ILC & ELC \\
\hline $\begin{array}{c}\text { Dengan } \\
\text { otoritas } \\
\text { pelaporan }\end{array}$ & Sel 1 & Sel 2 & Sel 3 & Sel 4 \\
\hline $\begin{array}{c}\text { Tanpa otoritas } \\
\text { pelaporan }\end{array}$ & Sel 5 & Sel 6 & Sel 7 & Sel 8 \\
\hline
\end{tabular}

\section{HASIL DAN PEMBAHASAN}

Sebelum eksperimen dilakukan, peneliti meyakinkan terlebih dahulu apakah subjek sudah paham tentang proses pembuatan laporan realisasi anggaran pada organisasi pemerintahan dan kondisi yang mungkin terjadi pada proses tersebut, seperti permintaan mark up dan masalah lainnya. Hal itu bertujuan untuk melakukan cek manipulasi atas subjek. Data demografi subjek peneltian ditunjukkan di tabel 3.

Penelitian ini bertujuan untuk menguji pengaruh faktor eksternal berupa otoritas atasan, retaliasi dan faktor internal yakni locus of control terhadap perilaku kecurangan dalam membuat laporan realisasi anggaran instansi pemerintah. Dalam penelitian ini, partisipan akan melaksanakan eksperimen dua tahap, pertama; menjawab kuesioner yang digunakan untuk mengukur locus of control, dan kedua; partisipan akan diberi suatu kasus yang disesuaikan dengan manipulasi dan sel peserta ditempatkan. Gambaran demografi subjek penelitian ditunjukkan pada tabel 3. Sedangkan statistik deskriptif penelitian dapat dilihat pada tabel 4 .

\begin{tabular}{cl}
\hline Keterangan & Jumlah \\
\hline Jenis kelamin & \\
Laki-laki & 14 orang \\
Perempuan & 57 orang \\
Semester & \\
Tujuh & 21 orang \\
Lima & 50 orang \\
\hline
\end{tabular}

\begin{tabular}{ccc}
\hline Faktor & \multicolumn{2}{c}{ Faktor retaliasi } \\
\cline { 2 - 3 } otoritas & Ada retaliasi & Tidak ada retaliasi \\
\hline Dengan & $\mathrm{Sel} 1$ & $\mathrm{Sel} 2$ \\
otoritas & $\mathrm{N}=18$ & $\mathrm{~N}=19$ \\
pelaporan & $\mathrm{JKP}=13$ & $\mathrm{JKP}=6$ \\
& $\mathrm{Rerata}=4,89$ & $\operatorname{Rerata}=2,47$ \\
& $\mathrm{DS}=2,03$ & $\mathrm{DS}=1,50$ \\
\hline Tanpa & $\mathrm{Sel} 3$ & $\mathrm{Sel} 4$ \\
otoritas & $\mathrm{N}=17$ & $\mathrm{~N}=17$ \\
pelaporan & $\mathrm{JKP}=10$ & $\mathrm{JKP}=4$ \\
& $\mathrm{Rerata}=3,29$ & $\mathrm{Rerata}=1,06$ \\
& $\mathrm{DS}=2,05$ & $\mathrm{DS}=0,83$ \\
\hline
\end{tabular}


Dari tabel 4 dapat disimak bahwa sel 1 atau kondisi terdapat otoritas atasan dalam pelaporan dan adanya retaliasi menunjukkan nilai J umlah Kecurangan Pelaporan (J KP) paling tinggi dari sel lain. Sedangkan sel 4 atau kondisi tidak terdapat otoritas atasan dalam pelaporan dan pula tidak terdapat retaliasi menunjukkan J KP paling rendah dari sel lain. Dengan demikian syarat pertama hipotesis la dan $1 b$ terpenuhi.

Sel anjutnya, untuk menguji apakah nilai J KP tersebut secara statistik berbeda signifikan antar sel, maka dilakukan uji kontras pada AN OVA (lihat tabel 5). Dari pengujian yang dilakukan, di peroleh ringkasan hasil sebagaimana yang ditunjukkan pada tabel 4. Dari pengujian between group ditemukan hasil bahwa sel 1 berbeda secara signifikan dengan sel 2, 3, dan 4 pada tingkat signifikansi 0,01 (pvalue: 0,000). Sedangkan sel 4 berbeda secara signifikan dengan sel 1, 2, dan 3 pada tingkat signifikansi 0,01 ( $p$-value: 0,000). Rincian lebih lanjut ditunjukkan di tabel lampiran.

Sedangkan untuk uji kontras, karena variance dari sampel berbeda, maka hasil pengujian dapat dilihat pada nilai Doesn't Assume Equal Variance dimana diperoleh p-value sebesar 0,000 untuk hipotesis la dan 0,002 untuk hipotesis lb. Dengan demikian, hasil uji kontras pada ANOVA di atas menunjukkan bahwa hipotesis $\mathbf{l a}$ dan $\mathbf{1 b}$ terdukung pada tingkat signifikansi 0,01. Rincian dapat disimak pada tabel 5 .

\begin{tabular}{ccc}
\hline Uji Statistik & Keterangan & Sig. \\
\hline Levene Statistic Hla dan H1b & Sel 1 $\neq$ Sel 2, 3, 4 & $0.000^{*}$ \\
ANOVA Hla (Between Group) & Sel 4 Fel 1, 2, 3 & $0.000^{*}$ \\
ANOVA H1b (Between Group) & Assume Equal Variance & $0.000^{*}$ \\
Contrast Test HIa & Doesn't Assume Equal Variance & $0.000^{*}$ \\
& Assume Equal Variance & $0.000^{*}$ \\
Contrast Test Hlb & Doesn't Assume Equal Variance & $0.002^{*}$ \\
\hline
\end{tabular}

Keterangan:

*Siginifkan pada level 0.01

\begin{tabular}{|c|c|c|c|c|}
\hline \multirow{3}{*}{$\begin{array}{c}\text { Faktor } \\
\text { otoritas }\end{array}$} & \multicolumn{4}{|c|}{ Faktor retaliasi } \\
\hline & \multicolumn{2}{|c|}{ Ada retaliasi } & \multicolumn{2}{|c|}{ Tidak ada retaliasi } \\
\hline & ILC & ELC & ILC & ELC \\
\hline \multirow{4}{*}{$\begin{array}{l}\text { Dengan } \\
\text { otoritas } \\
\text { pelaporan }\end{array}$} & Sel 1 & Sel 2 & Sel 3 & Sel 4 \\
\hline & $\mathrm{JKP}=3$ & $\mathrm{JKP}=10$ & $\mathrm{JKP}=0$ & $\mathrm{JKP}=6$ \\
\hline & Rerata $=3,86$ & Rerata $=5,55$ & Rerata $=1,46$ & Rerata $=3,86$ \\
\hline & $\mathrm{DS}=2,41$ & $\mathrm{DS}=1,51$ & $\mathrm{DS}=0,52$ & $\mathrm{DS}=1,25$ \\
\hline \multirow{4}{*}{$\begin{array}{c}\text { Tanpa } \\
\text { otoritas } \\
\text { pelaporan }\end{array}$} & Sel 5 & Sel 6 & Sel 7 & Sel 8 \\
\hline & $\mathrm{JKP}=3$ & $\mathrm{JKP}=7$ & $\mathrm{JKP}=1$ & $\mathrm{JKP}=3$ \\
\hline & Rerata $=2,10$ & Rerata $=5,00$ & Rerata $=0,78$ & Rerata $=1,36$ \\
\hline & $\mathrm{DS}=1,79$ & $\mathrm{DS}=0,82$ & $\mathrm{DS}=0,67$ & $\mathrm{DS}=0,92$ \\
\hline
\end{tabular}

Tabel 5.

ANOVA uji Kontras $\mathrm{Hla}$ dan $\mathrm{Hlb}$

Tabel 6. Statistik Deskriptif Desain Eksperimen $\mathrm{H} 2 \mathrm{a}$ dan $\mathrm{H} 2 \mathrm{~b}$

Hipotesis $2 a$ yang menyatakan bahwa perilaku kecurangan pelaporan ditemukan paling tinggi pada situasi terdapat otoritas atasan dan ada ancaman pembal asan (retaliasi) serta individu memiliki external locus of control (sel 2) dibandingkan situasi lainnya terdukung jika dilihat dari nilai J KP (lihat tabel 6).

Pada tabel 7, J KP sel 2 merupakan yang tertinggi dari sel Iainnya. Namun, bukti ini masih memenuhi syarat pertama. Untuk menguji apakah hipotesis benarbenar terdukung atau tidak, maka temuan tersebut harus dilakukan dengan uji kontras pada ANOVA. Berikut hasil uji kontras ANOVA hipotesis 2a dan 2b: 


\begin{tabular}{llc}
\hline \multicolumn{1}{c}{ Uji Statistik } & \multicolumn{1}{c}{ Keterangan } & Sig. \\
\hline Levene Statistic H2a dan H2b & & $0.000^{*}$ \\
ANOVA H2a (Between Group) & Sel 2 $\neq$ Sel 1, 3, 4, 5, 6, 7, 8 & $0.000^{*}$ \\
ANOVA H2b (Between Group) & Sel 7 $\neq$ Sel 1, 2, 3, 4, 5, 6, 8 & $0.000^{*}$ \\
Contrast Test H2a & Assume Equal Variance & $0.000^{*}$ \\
Contrast Test H2b & Doesn't Assume Equal Variance & $0.001^{*}$ \\
& Assume Equal Variance & 0.316 \\
& Doesn't Assume Equal Variance & 0.338 \\
\hline
\end{tabular}

Tabel 7.

ANOVA uji Kontras

$\mathrm{H} 2 \mathrm{a}$ dan $\mathrm{H} 2 \mathrm{~b}$

\section{Keterangan:}

*Siginifkan pada level 0.01

Dari tabel 7, dapat dilihat bahwa uji ANOVA between group atas $\mathrm{H} 2 \mathrm{a}$ signifikan pada tingkat 0,01 ( $p$-value: 0,000$)$. Selanjutnya, hasil uji kontras H2a dapat dilihat pada kolom Doesn't Assume Equal Variance yang nampak menunjukkan hasil yang signifikan pada tingkat 0,01 ( $p$-value: 0,000$)$. Dengan demikian hipotesis $2 a$ terdukung secara statistik. Sedangkan hipotesis 2 b yang menyatakan bahwa perilaku kecurangan pelaporan ditemukan paling rendah pada situasi tidak ada otoritas atasan dan tidak ada ancaman pembalasan (retaliasi) serta individu memiliki internal locus of control (sel 7) dibandingkan situasi lainnya ternyata tidak terdukung. Hal itu dapat disimak pada tabel 6 dimana JKP terendah justru berada pada sel 3 atau pada kondisi terdapat otoritas pelaporan namun tidak terdapat retaliasi. Dengan tidak terpenuhinya syarat pertama ini, maka meskipun uji ANOVA H2b between group signifikan pada tingkat 0,01 ( $p$-value: 0,000 ), hipotesis $2 \mathrm{~b}$ tidak terdukung. Tidak terdukungnya H2b juga nampak pada nilai $p$-value uji kontras di tabel 6 pada Doesn't Assume Equal Variance sebesar 0,338 (> 0,05 dan 0,10).

\section{SIMPULAN}

Peneletian ini bertujuan untuk menguji pengaruh faktor stuasional berupa otoritas atasan dan ancaman pembalasan (retaliasi) serta faktor individual berupa locus of control terhadap perilaku kecurangan pelaporan laporan realisasi anggaran di lembaga pemerintahan. Dari hasil pengujian hipotesis ditemukan bahwa H1a, $\mathrm{H} 1 \mathrm{~b}$, dan H2a terdukung, yang artinya kondisi dimana terdapat otoritas atasan untuk melakukan kecurangan, ditambah lagi adanya ancaman (retaliasi) dari atasan jika perintah tidak dilakukan cenderung akan menjadikan seseorang bertindak untuk tidak etis, yakni membuat laporan realisasi anggaran yang tidak sesuai. Disamping itu, individu dengan locus of control eksternal, pada kondisi mendapat otoritas untuk membuat laporan curang dan mendapat ancaman jika tidak melaksanakan perintah tersebut, akan cenderung untuk berlaku lebih tidak etis, yakni dengan menuruti perintah atasan tersebut untuk membuat laporan curang dibandingkan individu dengan locus of control internal.

$\mathrm{H} 2 \mathrm{~b}$ yang menyatakan saat tidak ada otoritas atasan dan tidak ada retaliasi serta individu memiliki tipe locus of control internal maka tingkat kecurangan menjadi paling rendah dibandingkan dengan situasi lainnya, dalam penelitian ini ternyata tidak terdukung. Hal itu dapat disimak dari tabel statistik deskriptif pengujian hipotesis $2 \mathrm{a}$ dan $2 \mathrm{~b}$, yang membuat laporan curang paling sedikit bukan berada pada situasi tidak ada otoritas atasan dan tidak ada retaliasi serta individu memiliki tipe locus of control internal (sel 7), melainkan berada pada kondisi ada otoritas atasan tetapi tidak ada retaliasi dan individu memiliki tipe locus of control internal (sel 3). Akan tetapi secara statistik, jumlah kecurangan di sel 3 dan sel 7 tidak berbeda signifikan.

Jika dibandingkan kedua kondisi (sel 3 dan 7) tersebut dengan kondisi dimana terdapat retaliasi tanpa memperhitungkan apakah ada otoritas atau tidak 
dengan tetap menempatkan individu yang memiliki tipe locus of control internal (sebagaimana pada sel 1 dan 5), maka jumlah yang melakukan kecurangan pada kedua sel tersebut sama dan lebih tinggi jumlah kecurangan yang dilakukan daripada kondisi tidak terdapat retaliasi (sel 3 dan 7). Hal tersebut mengindikasikan bahwa faktor situasional berupa retaliasi memiliki pengaruh yang lebih kuat daripada adanya otoritas atasan untuk membuat kecurangan.

Di samping itu, meski hipotesis $2 \mathrm{~b}$ tidak terdukung, jika dibandingkan antara individu yang memiliki tipe locus of control internal dan eksternal, maka mereka yang memiliki tipe eksternal akan cenderung lebih patuh untuk membuat laporan curang ketimbang mereka yang bertipe internal (lihat tabel 5).

Dari hasil penelitian ini, implikasi penting yang menjadi masukan, khususnya bagi kalangan praktisi yang membuat kebijakan adalah; perlu kiranya untuk memperhatikan individu yang menempati posisi berkaitan dengan pelaporan keuangan. Alangkah baiknya jika posisi tersebut ditempati oleh mereka yang memiliki tipe locus of control internal, karena akan mampu mengurangi risiko kecurangan pelaporan. Selain itu, posisi pembuat laporan keuangan di lembaga pemerintah seharusnya bebas dari tekanan pihak manapun agar mereka mampu untuk bekerja jujur dan membuat laporan sebagaimana yang seharusnya. Akan tetapi tentu hal ini sulit karena lingkungan kerja menuntut setiap anggota organisasi untuk saling berinteraksi. Oleh karenanya, setidaknya hal itu perlu menjadi perhatian bagi pimpinan dan pembuat kebijakan.

Penelitian ini tentu memiliki keterbatasan yang melekat, diantaranya; pertama, penelitian ini menggunakan partisipan atau subjek mahasiswa yang syarat dengan pro-kontra mengenai sah tidaknya subjek mahasiswa mewakili subjek yang seharusnya dipilih dari praktisi. Meski begitu, peneliti sudah melakukan manipulasi kondisi agar partisipan merasa bekerja di lingkungan pemerintahan dan dibawahi oleh seorang atasan. Akan tetapi, manipulasi bisa saja tidak berjalan sebagaimana keinginan peneliti secara sempurna. Maka, penelitian selanjutnya menjadi penting untuk diuji pada subjek yang sudah bekerja di ranah sektor publik sebagai akuntan atau staf yang menangani bagian pengelolaan keuangan instansi khsusnya pelaporan.

Kedua, Walaupun manipulasi dilakukan dengan sedemikian rupa, tidak menutup kemungkinan adanya faktor lain yang tidak terkontrol oleh peneliti. Meski demikian, peneliti sudah melakukan randomisasi kepada subjek penelitian agar faktor-faktor lain yang mungkin berpengaruh terhadap perilaku etis subjek dapat ter-eliminir. Ketiga, subjek penelitian didominasi oleh perempuan. Hal ini dikarenakan penelitian ini bersifat suka rela, dan rupanya yang mau berpartisipasi dalam penelitian ini kebanyakan adalah mahasiswi (perempuan). Oleh karenanya penelitian selanjutnya diharapkan harus membagi secara proporsional subjek penelitian.

Keempat, penentuan karakteristik subjek apakah masuk dalam kategori $10^{-}$ cus of control internal atau eksternal hanya dibagi berdasarkan posisi nilai perhitungan jawaban subjek dengan nilai median, dimana jika nilai perhitungan lebih besar dari nilai median maka masuk kategori eksternal dan jika lebih kecil maka masuk kategori internal. Padahal, dalam kehidupan nyata, menentukan karakteristik seseorang apakah masuk dalam kategori locus of control internal atau eksternal sulit untuk dilakukan dan tidak seseder-hana seperti yang dilakukan oleh peneliti.

Terakhir, karena penelitian ini menggunakan desain eksperimen yang terkenal dengan kuat validitas internal tetapi lemah dalam validitas eksternal, maka pembaca disarankan untuk berhati-hati untuk melakukan penyimpulan yang bersifat umum atau menjeneralisir hasil penelitian ini pada kondisi dan situasi lain yang serupa. 
The Evidence of Goodwill...

\section{DAFTAR PUSTAKA}

Allmon, D. E., Page, D., \& Roberts, R. (2000). Determinants of Perceptions of Cheating: Ethical Orientation, Personahty and Demographics. Journal of Business Ethics, 23, 411-422.

Cohen, J. F., Pant, L. W. \& Sharp, D. J., Culture-Based Ethical Conflicts Confronting Multinational Accounting Firms, Accounting Horizons (September 1993) pp. I-13.

Day, N. E., Hudson, D., Roffol, P., \& Robert, D. (2011). Student or situation? Personality and classroom context as predictors of attitudes about business school cheating. Social Psychol Educ, 14, 261-282.

Kerlinger, F. D., \& Lee, H. B. (2000). Foundations of Behavioral Research (4 Edition.). United States of America: Earl McPeek.

Liyanarachchi, Gregory \& Chris Newdick (2009) The Impact of Moral Reasoning and Retaliation on Whistle-Blowing: New Zealand Evidence. Journal of Business Ethics (2009) 89:37-57

Milgram, S. (1974). Obedience to Authority An Experimental View. Harper \& Row, Publisher, Inc.

Murphy, P. R., \& Mayhew, B. W. (2012). The Impact of Authority on Reporting Behavior. SSRN Electronic Journal. SSRN Electronic Journal, (Electronic copy available at: http://ssrn.com/abstract=2026449).

Nahartyo, E. (2012). Desain dan Implementasi Riset Eksperimen. Yogyakarta: UPP STIM YKPN.

Ponemon, L. A., (1992). Auditor Underreporting of Tie and Moral Reasoning: An Rxperimental Lab Study. Contemporay Accounting Research pp. 171- 189.

Raab, M. S. (1987). Detecting and Preventing Financial Statement Fraud: The Roles of the Reporting Company and the Independent Auditor. Yale Law \& Policy Review, 5(2), 514-535.

Rotter J.B. (1990). Internal versus External control of reinforcement. American Psycologist, Vol. 45. No.4

Rutledge, Robert W \& Khondkar E. Karim (1999) The influence of self-interest and ethical considerations on managers' evaluation judgments. Accounting, Organizations and Society 24.

Singleton, T. W., \& Singleton, A. J. (2010). Fraud Auditing and Forensic Accounting (4th edition.).

Trevino, L. K., (1986) Ethical Decision Making in Organizations: A Person-Situation Interactionist Model, Academy of Management Review pp. 601-617.

Tsui, Judy S L. \& Ferdinand A Gul. (1996). Auditors' Behaviour In An Audit Conflict Situation: A Research Note On The Role Of Locus Of Control And Ethical Reasoning. Accounting, Organizations and Society, Vol. 21, No. 1. PP. 41-51. 